\title{
Earthquake Emergency Rescue Geography Support Platform and Application Cases
}

\author{
Yuan ZHANG \\ National Earthquake Response Support Service \\ Beijing, China \\ e-mail: zhangyuanwork@163.com
}

Huajia CHEN

Yi ZhiRui (China) InforwareLab Information Technologies Beijing, China

\begin{abstract}
The earthquake emergency succor is a system engineering with cross-sectoral, multi-disciplinarity and multi-domain, which needs a rapid emergency response capability. The earthquake emergency rescue geography support platform construction conception has been put forward based on the earthquake emergency rescue in our country's present situation and the needs of the business by this thesis. The seismic spatial data has been considered as the support basic data for the earthquake emergency rescue geography support platform, and the professional seismic analysis model and the advanced GIS geographic platform technology as the technical support. Besides, the map has been considered as the main information carrier in order to offer the professional and authoritative disaster information to all kinds of audience personnel during the earthquake emergency succor.
\end{abstract}

Keywords-earthquake emergency succor GIS; geographic support platform; application mode

\section{INTRODUCTION}

Earthquakes caused a huge damage to the humans living safety, social and economic development, social stability because of its sudden and huge destructions. Many earthquakes occurred in our country. Mainland China has experienced five seismic active periods since the 20th century [1], especially when we get into the 21 st century, earthquakes including Wenchuan Earthquake in 2008(8.0 on the Richter scale), Yushu Earthquake in 2010 (7.1 on the Richter scale) and YaAn Earthquake in 2013(7.1 on the Richter scale) brought serious personal casualty and property loss to the local people. These put forward a new requirement to the work of earthquake forecasting and prediction, seismic prevention and disaster mitigation, and the emergency rescue of our country. In the system of earthquake disaster preparedness and mitigation, monitoring and prediction is the basis, disaster prevention is the emphasis, and emergency rescue is the key [2]. Live aid and reduce the damage is the aim of the earthquake emergency rescue work, which need professional workers, advanced equipment, and the science of command decisions are more needed.

\author{
Kang LIU \\ National Earthquake Response Support Service \\ Beijing, China
}

Linfeng ZHEN

Yi ZhiRui (China) InforwareLab Information Technologies Beijing, China

GIS (Geographic Information System, geographical information system) is a subject which carries out the research with the space data collection, management, analyze and drawing the picture. The application of GIS technology during the earthquake emergency rescue can be date back to 1990s [3]. After some decades, GIS offered an important influence in post-earthquake statistics, seismic model analysis, to guide the post-disaster emergency rescue work and other aspects works[4].With the swift and violent development of computer technique, surveying and mapping technology, remote sensing technology, the GIS technology is moving in the direction of $3 \mathrm{~S}$ integration practical platform. The construction of the idea for the earthquake emergency rescue geography support platform has been described based on GIS geographic platform technology by this thesis, and to build a shared coordinated emergency geographic support platform with an integration of all kinds of resources, open interface, can be used by all the people which can improve the effective of the earthquake emergency rescue work immensely, guarantee the earthquake emergency rescue work of scientific decision-making forcefully, improve the management level of the earthquake emergency rescue work.

\section{II.EARTHQUAKE EMERGENCY RESCUE DEVELOPMENT PRESENT SituATION AND THE DEMAND [5]-[6]}

As far as the timeliness, earthquake emergency rescue work has characters of burst strongly and needing a quick response. As far as the working content, it includes research and judgment for the disaster, the emergency rescue force transfer, carrying out the on-site rescue work, acquiring and processing of various kinds of information, etc, which need to be proceed orderly, rapidly and efficiently. The construction of various "five years" plan of earthquake emergency command system and the major earthquake exercises in the couple of years have been experienced by our country, and the ability to get and handle the information of the earthquake emergency rescue, the ability of the response and disposal for the earthquake, the ability of the comprehensive supportability have been improved. Besides, a series policies, laws and regulations have also been put 
forward which make a preliminary construction for the relatively perfect system of earthquake emergency rescue. However, the earthquake emergency rescue system of our country starts relatively late, and the earthquake emergency rescue itself is a complex in many areas department with multidisciplinary integrated. In recently years, some shortcomings and disadvantages have been exposed from the situation of the major earthquake emergency rescue. Zhuang Li (2009) et al. compared our country to America, Japan and other developed countries in the aspect of earthquake emergency response management, and pointed out that our emergency mechanism, organizational system, insurance of the science and technology, the emergency response plan form, the legal system should been further improved and perfected [7]. Next, the function of the GIS platform technology will be selective analyzed by this thesis combining with the earthquake emergency rescue business requirements.

\section{A. Seismic Spatial Database Construction Requirements}

The seismic spatial database is one of the most important basic data of the earthquake emergency rescue. The seismic spatial database includes: Basic geographic database, the population distribution of economic data, the school of medical institution distribution data, the fire rescue power distribution data, the data of geological structure, road net data model, railway data and so on. Building up the seismic spatial database is a continuous system engineering, which needs the country, province, city, suburb, even the villages and towns at all levels of the earthquake and the government all work together. During the construction of the seismic spatial database, the GIS technology is a core technology. It needs the support from the GIS technology in spatial data warehouse, reserve, refresh, management, distribution application and other aspects.

\section{B. Earthquake Emergency Disaster Information Processing Needs [8]}

Earthquake emergency disaster information is the core element of the earthquake emergency succor. Earthquake emergency disaster information comes from every aspects, such as those from the local reported casualty figures, the quake zone image data which took by the aviation and satellite remote sensing, the data got by the rescuers in the air. These data are numerous and confused in succession, which need building the comprehensive seismic spatial database to carry out the value information through the most accurate professional processing, which means transferring the data to the information, and designing to the information production in order to service the emergency rescue command decisions as well as publish to the social public in time. Therefore, we need a comprehensive platform to integrate the spatial database and all kinds of earthquake emergency disaster information, and the map is the necessary vector which can carry all kinds of earthquake emergency rescue information, just as what is called "one picture is better than thousands of sentences".

\section{Earthquake Emergency Rescue Project Application Building Demand}

As mentioned above, we talked about getting the information production from the various seismic emergence database. To realize this procedure, we need the support of all kinds of special application system, and the earthquake emergency rescue rapid cartography system, disaster research and judgment system, dynamic plotting system, information release system, the major disaster project application, the professional analysis model of applications of the system and so on. These application systems are not always rebuilt when earthquake occurs. Instead, they are based on the application system to realize the rapidly construction via the simple configuration. The professional analysis of what the setting region spatial data and the import all kinds of disaster data are what the personnel applying doings in order to apply the insurance to the earthquake emergency rescue.

\section{Earthquake Emergency Rescue Work Mechanism Construction Requirements}

Earthquake emergency rescue work needs multiple departments work together. No matter the front rescue, command or the decision, insurance in the back. How to integrate the resource we have, to promote information sharing, to realize the transverse vertical exchange of the Internet, to maximize the value of resources are the problems which earthquake emergency rescue work faces mechanism construction. The advanced science and technology technical support is essential to realize teamwork among the different department, admittedly construction of policies and regulations and system is indispensable. Nowadays, the rapid development of the advanced communication technology, mobile internet technology and cloud computing technology make the impossible in the past possible, as well as offering the necessary condition to the earthquake emergency rescue departments should work together.

\section{E. Earthquake Emergency Rescue Audience Analysis}

Earthquake emergency rescue work mainly include: command decision-making departments, on-the-spot rescuers, professional analysis, social public, the masses, etc. All kinds of audience personnel play different roles in different situations during the earthquake emergency rescue as well as have the different needs to the earthquake emergency rescue information. Lots of detailed disaster information and professional analysis results have been needed by the command decision-making departments in order to carry out the scientific decision, reasonable deployment of aid and supplies; the clear rescue task arrangement has been needed by the rescue worker and arrive the worst-hit area on the first time as well as carry out the rescue work. Besides, giving the feedback of the site conditions to the emergency command center; the professional analysis according to the seismic analysis model based on professional all kinds of data and design all kinds of information products; the authority of the disaster information which needed by the social public and give the suitable help according to the own ability; the authority of 
the disaster information is also needed by the masses in order to get the information about their relative as well as feedback on their current items are most needed, etc.

\section{EARTHQUAKE EMERGENCY RESCUE GEOGRAPHY SUPPORT PLATFORM CONSTRUCTION}

The GIS geographical platform technology has four characters which are integration, openness, universal and synergy, and also showed a trend of application of multi-terminal and resources in the cloud. To build earthquake emergency rescue geography support platform with considered the GIS geographical platform technology as the core. The exposition in the following is from the positioning, architecture, application model and other aspects.

\section{A. Platform Positioning}

1) Earthquake emergency rescue of all kinds of data resources integration platform:

Earthquake emergency rescue geography supports platform based geographic data sets, the professional earthquake data, and the rescue force data, the population economy data, point of interest data have been gathered as a whole, and publish into the standard web service via GIS service software. The unified identity authentication mechanism has been offered by platform, and the platform can be quickly index, browse all kinds of resources via identification which make all the datum as plain as daylight as well as offer the basic GIS data support for the leader to analyze and to make the decision, and for the business personnel office mapping.

2) Earthquake emergency rescue rapid cartography and publishing platform:

The urgent rescue rapidly drawing template has been offered by the platform which based on the online mapping function or enterprise integration plug-in that provided by, and which can make out a thematic maps of emergency rescue rapidly as well as publish to share online maps to earthquake emergency rescue workers so as to meet the needs of the earthquake emergency rescue rapidly drawing and sharing for the various people.

3) Earthquake emergency rescue collaborative geographical support platform:

Based on the information department management, results content management and sharing mechanism which offered by the platform can realize the teamwork for across departments across the business in order to provide a powerful spatial data and the technique support for the earthquake emergency succor.

4) Earthquake emergency rescue should build the GIS application platform structures quickly:

The earthquake emergency rescue geography support platform is an open platform, the business application system fleetly interface has been provided as well as creating rich variety of application systems via the simple configuration. Meanwhile, the professional application of earthquake emergency rescue systems can be designed through the web port, the mobile terminal standards development interface.

\section{5) Daily thematic map making and sharing platform:}

The daily use of seismic data statistical figure, Distribution of thematic charts and etc can be designed based on the all kinds of basic geographic data and seismic spatial data which offered by the platform, and shared to the state seismological bureau in the system by the platform as well as sharing the work resorts and improve the working efficiency.

6) The society of information query platform:

The most concerned and the most detailed, the seismic information after the quake can be achieved by all kinds of authority, professional data, the social public, the masses which offered by this platform, and that is good for carrying out save yourself rescue work after the quake as well as reducing the affected areas of the chaos in a way.

\section{B. The Platform Architecture Design}

The earthquake emergency rescue geography support platform architecture divide into the data layer, software layer, the platform layer and application layer four aspects, which is shown as following:

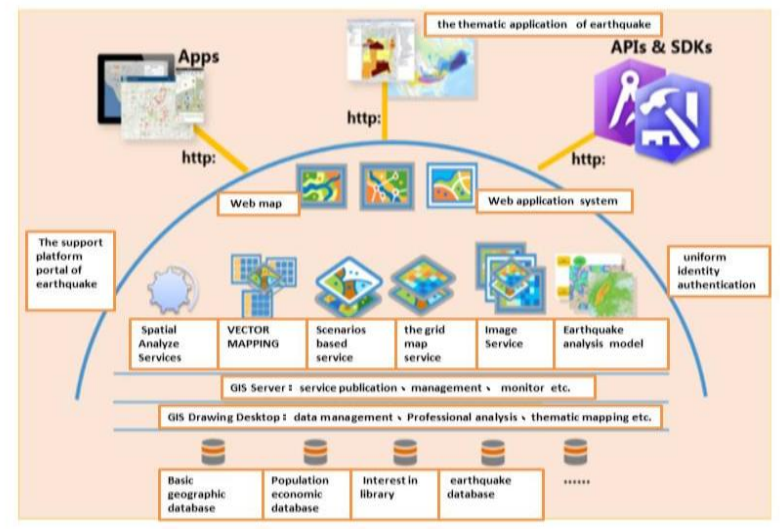

Figure 1. Earthquake emergency rescue geography support platform architecture diagram

The data layer: including various data needed by earthquake emergency rescue operations, such as basic geographic database, population economic database, interest in library, the earthquake professional database, rescue force database, etc. Actually, the data layer is the seismic spatial database, which relies on the GIS professional geographic database model, and reserve the nonobjectivepoint, line, surface, volume, form of all kinds of spatial data related as well as building the effective mechanism of management and update effective mechanism of management and update so as to ensure the accuracy and timeliness of the data.

The software layer: mainly including the professional GIS mapping software and services release software to realize the management analysis for the seismic spatial data as well as designing to the thematic map, and to publish out into the map service.

The platform layer: it includes the various project outcomes data services (vector, grid, image, etc), spatial analyze services, seismic analysis model and professional service, online map, online App and so on. The geographic support platform web portal is the universal resource access, 
and the uniform identity authentication ensures the safety of the platform resource.

The application layer: based on the various APIs, APP, SDKs offered by platform to build the APP based on the needs of the earthquake emergency rescue operations, such as the disaster research and judgment system, the disaster dynamic plotting system, the rescue power distribution system, the quick draw graphics system, etc, and these system call on the platform resource via the standards development interface so as to improve the ability of the platform application.

\section{Platform Application Mode}

The customers of the earthquake emergency rescue geography support platform services include social public, rescue worker, industry professional users, the command and decision makers, platform maintenance or developers, the data processing and mapping professionals and etc. During the quake emergency succor, we can get the first hand earthquake disaster data via satellite remote sensing, unmanned aerial vehicle flight, the rescuers, the earthquake monitoring network and so on, reserving them in the platform database; the data processing and mapping professionals cure the loss database through the GIS data-processing software, the platform for rapid cartography system, the professional seismic analysis system and others in order to make them to the emergency disaster information products as well as published as a service via the GIS data-processing software; the information production can be offered to the command and decision makers, auxiliary decision analysis. At the same time, to build the thematic maps online, project application system through the platform maintenance personnel or developers to the social public, rescue workers or industrial applications, command and decision makers; the latest information on the disaster and the rescue progress can be achieved by social public. To the command and decision makers, on one hand, the valuable reference information has been got by them; on the other hand, they can make out the deployment decision, command various forces so as to carry out the rescue. When the newest information has been achieved by the rescue worker, they also can carry out the rescue actively according to the unified command. The analysis result of the multi-domain and the multidisciplinary by people according to the own professional knowledge analysis to make up for the deficiency. During this application, the integration of the various data resource, the teamwork of the multi-department has been involved as well as the needs for the various customs have been covered. Platform overall application mode as shown in the figure below:

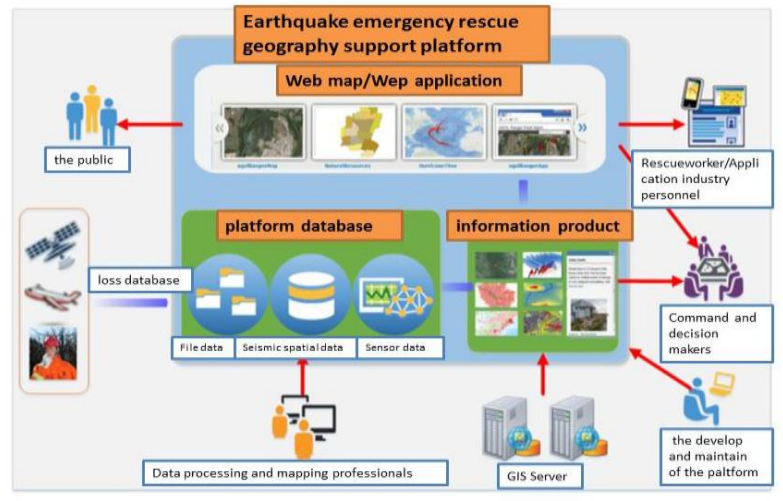

Figure 2. Earthquake emergency rescue geography support platform application model

\section{PlatForm CASE}

\section{A. Case 1: The Thematic Application of the Online Platform of Nepal Based on ArcGIS}

In April, 25th in 2015, an 8.1 magnitude earthquake happened in Nepal (28.2 degrees north latitude, 84.7 degrees east longitude) at twenty eleven, which caused huge personnel casualty and property damage to the local people. After the Esri company learned the disaster, and built the special applications of the Nepal based on the public cloud deployment in the amazon cloud environment GIS platform (http://nepalem.maps.arcgis.com/home/). As following:

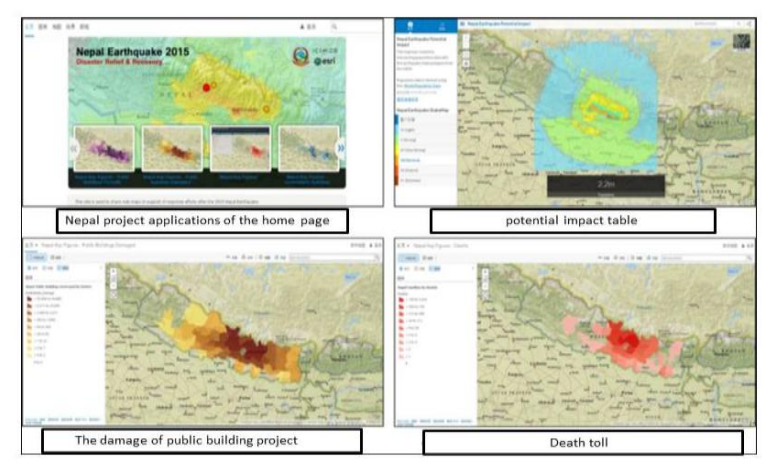

Figure 3. Esri company (America) build the " $4 \bullet 25 \mathrm{Nepal}$ " special applications of the earthquake

A series special applications has been designed via special applications of the structures of Nepal by Esri company (America), such as thematic map damaged buildings, casualties thematic map, rescue operation and etc. The various straightforward maps have been designed by this special application which has been based on basic map service offered by this platform, the online mapping services and the application template in order to let the command and decision makers, aid workers and the public have a clearly notice about the disaster information.

\section{B. Case 2: The Australian State of Victoria Fire Emergency Management Geographic Platform}

The fire is a constant companion for the scenery of Australian. However, the vegetation, landform and the 
climate of Australia which make this place become as one of the most likely places to cause forest fires in the world. In 2009 summer, the Australian state of Victoria has suffered catastrophic forest fire, which causes the huge losses of life and property. Therefore, the Australian state of Victoria drew lessons from the past, and a series of policy measures have been formulated. Besides, including a very important measure the geographic platform fire emergency management eMap has been built so as to improve the basic operating ability and cooperation ability of the all fire authority in the Victoria area. Platform interface as shown in the figure below:

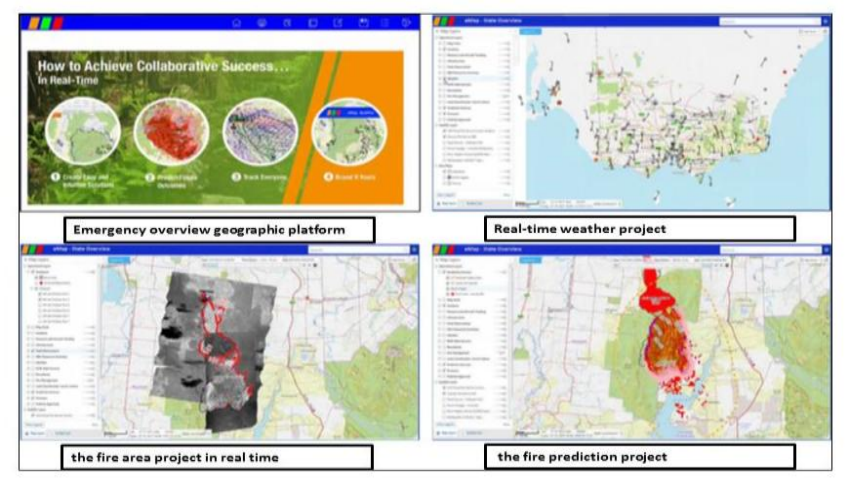

Figure 4. The Australian state of Victoria fire emergency management geographic platform

This platform which based on the ArcGIS platform software structures, and integrate all kinds of real-time data resources which have been needed during the fire-fighting procedure(meteorological data, viewdata, vehicles and personnel data, etc)and that can offer the real-time response view to the related department; the fire prediction analysis model has been offered; the variety of mobile devices has been supported, and the dedicated application has been offered for the outdoor workers, which can collect data by wild offline and print figure it out. All kinds of fire real-time information sharing have been realized via this platform. Besides, the collaborative work efficiency for the Victoria fire power has been improved greatly by simple configuration can be customized a variety of applications. The geographic platform fire emergency management has been built by Victoria state government which has certain reference significance to the earthquake emergency rescue geography platform construction.

\section{V.EPILOGUE}

Earthquake emergency succor is a system working with cross-sectoral, multi-disciplinarity and multi-domain, which needs the protection of perfect law and regulations, completes organization management system, excellent talent team and advance science and technology strength. Business requirements analysis of earthquake emergency rescue and audience demand analysis have been based on this thesis, and the conceived economic plan has been put forward based on the earthquake emergency rescue geography support platform. The project application templates via this platform to integrate all kinds of data resources of earthquake emergency rescue which can build all kinds of special application rapidly and share to the members of the organization and the social public in order to offer the information support for the emergency rescue command decisions.

\section{REFERENCES}

[1] Institute of earth environment, Chinese academy of sciences, the basic information of the earthquake, http://www.ieecas.cn/kxcb/kpdt/200805/t20080513_1662976.html.20 08-05-13.

[2] DeShi Xu, Xiong Sun, Hong Chen,etc. The summary of China earthquake emergency rescue work $[\mathrm{J}]$. Recent Developments in World Seismology, 2004, (6):1-7.

[3] Jun Ding, Dan Wang. The application of GIS in earthquake disaster investigation $[\mathrm{J}]$ Geological hazards and environmental protection, 1996, 7(2):1-5.

[4] DongPing Li, Yuan Yao. The development trend of GIS and the realisation technique of the digital earthquake emergency relief [J]. Computer Technology and Development, 2011, 21(1):214-217.

[5] FangHao Zhang, YongQiang Li, etc. The discussion of the provincial earthquake emergency information public service platform design $[\mathrm{J}]$. technology for earthquake disaster prevention, 2015, 10(3):657-663.

[6] DeShi Xu, JianFa Huang. The thinking of the earthquake emergency and rescue in our country the development $[\mathrm{J}]$. Recent Developments in World Seismology, 2006, (10):1-8.

[7] Li Zhuang, HuiYing Gao, LiMing Tan. China and Japan earthquake emergency management pattern comparison $[\mathrm{J}]$. World Earthquake Engineering, 2009, 25(3):97-101.

[8] Man Dong, TianQing Yang. Earthquake emergency disaster information classification $[\mathrm{J}]$. technology for earthquake disaster prevention, September, 2014(4):937-943. 